\title{
Symbols in Wittgenstein's Tractatus
}

\author{
Colin Johnston
}

This paper is concerned with the status of a symbol in Wittgenstein's Tractatus. It is claimed in the first section that a Tractarian symbol, whilst essentially a syntactic entity to be distinguished from the mark or sound that is its sign, bears its semantic significance only inessentially. In the second and third sections I pursue this point of exegesis through the Tractarian discussions of nonsense and the context principle respectively. The final section of the paper places the forgoing work in a secondary context, addressing in particular a debate regarding the realism of the Tractatus.

\section{Sign and Symbol}

\section{1}

Something of great importance in the Tractatus is the distinction of symbol from sign. This is set out in the passage headed by section 3.32:

A sign is what can be perceived of a symbol. (TLP 3.32)

A sign is the perceptible aspect of a symbol. It is a mark on a piece of paper, or a sound. As Wittgenstein was later to write:

The sign is the written scratch or the noise. (LWL p26)

In contrast to this it might be expected that a symbol will be a meaningful sign, a sign considered together with a meaning. Occurrences of a symbol, the suggestion would be, will be those occurrences of its sign in which the sign bears a certain meaning. Thus Max Black and Ian Proops write:

A symbol is a sign together with its meaning or sense. (Black 1964: 130)

The "names" spoken of in the Tractatus are not mere signs (i.e., typographically or phonologically identified inscriptions), but rather signs-together-with-their-meanings — or “symbols.” (Proops 2004: §1)

But it is doubtful that this identification of a Tractarian symbol is correct, for at Tractatus 3.323 we find:

In the proposition, 'Green is green' - where the first word is the name of a person and the last an adjective - these words do not merely have different meanings: they are different symbols. (TLP 3.323)

Difference of symbol, Wittgenstein implies, is strictly stronger than difference of meaning. One and the same symbol may have different meanings on different occasions. ${ }^{1}$

A symbol does not, it would appear, involve a meaning as a matter of its identity. What it does so involve, however, is a 'mode of signification':

So one and the same sign (written or spoken, etc.) can be common to two different symbols - in which case they will signify in different ways [sie bezeichnen dann auf verschiedene Art und Weise]. (TLP 3.321)

In everyday language it very frequently happens that the same word has different modes of signification [verschiedene Bezeichnungsweisen] - and so belongs to different symbols.

(TLP 3.322)

Difference of symbol with identity of sign implies difference of mode of signification, and difference of mode of signification implies difference of symbol. 
These moves are important; we will do well to get as clear about them as possible.

Considering two symbol occurrences, let SY be the proposition that they are occurrences of the same symbol and let ME be the proposition that the two symbols occur there with the same meaning. With each of these symbol occurrences there will occur a sign; let SI be the proposition that the two occurring signs are the same sign and let MO be the proposition that the two signs occur there with the same mode of signification. Assuming that a symbol has just one sign, that is that SY entails SI, we can derive the following results. First from Tractatus 3.322 we have that SY implies MO. Conversely, Tractatus 3.321 gives that SI and MO jointly entail SY. Thus SY entails, and is jointly entailed by, SI and MO. Regarding ME, by contrast, Tractatus 3.323 gives that it is not entailed by SY. Adding to this the possibility of synonyms, that is that ME does not entail SI, we obtain that SY neither entails nor is entailed by ME. The result is thus that whilst a symbol determines both a sign and a mode of signification of that sign, and that conversely a sign together with a mode of signification determines a symbol, what a sign may mean on some occasion of its occurrence is a matter not determined by what symbol is there occurring. ${ }^{2}$ A symbol is not, as Proops and Black suggest, a sign considered together with a meaning, but rather a sign considered together with a mode of signification.

This conclusion is of course not taken as having been decisively established: we have looked here at only at one passage from the Tractatus. Nonetheless it will constitute a working hypothesis to be confirmed through the discussions below.

\section{2}

Let's investigate Wittgenstein's talk of a 'mode of signification'. We were told in section 3.323 that in the sentence 'Green is green' the two instances of the sign 'green' are instances of different symbols, and that this is entailed by the fact that the first is the name of a person and the second is an adjective. Now something entailed here weaker than difference of meaning is difference of syntactic type. The thought is thus possible that a mode of signification of a sign will be, for Wittgenstein, a syntactic use. A sign signifying in a certain way will be a sign in use as a syntactic element of a certain kind (as an adjective, perhaps). Of course, syntax here will mean logical syntax rather than surface syntax, and the proposal will accordingly be that a mode of signification is a logico-syntactic employment.

Support for this suggestion is found in Wittgenstein's idea of conceptual notation:

In order to avoid [philosophical] errors we must make use of a sign-language that excludes them by not using the same sign for different symbols and by not using in a superficially similar way signs that have different modes of signification: that is to say, a sign language that is governed by logical grammar - by logical syntax. (TLP 3.325)

In a conceptual notation we shall avoid philosophical errors or confusion firstly by not allowing two different symbols to share a sign (a failing displayed in 'Green is green'), and secondly by not using in a 'superficially similar way signs that have different modes of signification'. More, this latter is the achievement of a language governed by logical syntax: a language governed by logical syntax is transparent regarding the sameness and difference of modes of signification of its signs. What is achieved, however, by a language governed by logical syntax is, precisely, a transparency regarding the logico-syntactic types of the propositional elements in play at any point - a transparency, that is, regarding the logico-syntactic employment at any point of the language's signs.

Further support both for the identification of a mode of signification with a syntactic use, and also for the proposal that a symbol is a sign together with a mode of signification, may be gained first by noting that a key symbol type for Wittgenstein is the proposition:

I shall call any part of a proposition that characterises its sense an expression (or a symbol). (A proposition is itself an expression.) (TLP 3.31)

and that the signifying of a proposition is a depicting:

A proposition is a picture of reality. (TLP 4.01)

To these, we may then add:

A propositional sign with its mode of depiction is the proposition. (PTLP 3.2)

and: 
If ... then infinitely many propositions of different content follow LOGICALLY from that first one. And this of itself shews that that proposition itself was a matter of fact infinitely complex. That is, not the propositional sign by itself, but it together with its syntactical application. (NB p64)

A symbol, for example a proposition, is a sign together with a mode of signification. Or again, it is a sign together with a syntactical application. A mode of signification, the proposal will thus run, is a syntactic employment. A symbol is a syntactic element.

Something that may occasion concern here, however, is the introduction of propositions as symbols. Does this not threaten our suggestion above that a symbol does not include its meaning? It is, one might well suppose, essential to a proposition that it means what it does. If two propositions differ in meaning then they are different propositions. In preparation for tackling this point, let's look quickly at a couple of basic features of Wittgenstein's semantics and metaphysics.

\section{3}

A proposition, we have just seen, 'is a picture of reality' (TLP 4.01), and of pictures Wittgenstein writes:

A picture represents [stellt ... dar] a possible situation in logical space. (TLP 2.202)

What a picture represents [darstellt] is its sense [sein Sinn]. (TLP 2.221)

Beside the proposition, the other key symbol type is the name:

Names are the simple symbols. (TLP 4.24)

of which we find:

A name means [bedeutet] an object. The object is its meaning [seine Bedeutung]. (TLP 3.203)

Now without intending it to be understood that there is a single species of meaning going on here (that representing a situation is the same kind of achievement as standing for an object), I want to adopt for the purposes of this paper a terminology of 'semantic significance' such that for a proposition to represent a situation is for it to be semantically significant and for a name to stand for an object is for it to be semantically significant. Further, we can introduce talk of a symbol's 'semantic value' such that the semantic value of a name is the object it stands for - its referent ('seine Bedeutung' (TLP 3.203)), and the semantic value of a proposition is the situation it represents - its sense ('sein Sinn' (TLP 2.221)). ${ }^{3}$ (Whilst this talk does pass by distinctions of importance in the Tractatus, these distinctions will not be crucial to the concerns of this paper. $)^{4}$

Turning to the objects and situations themselves, something that will be of importance to us is Wittgenstein's distinction between form and content. A symbol, Wittgenstein writes, 'is the mark of a form and a content' (TLP 3.31); what is marked by a symbol - its semantic value - is at once a form and a content. Objects, we are told in particular, 'make up the substance of the world' (TLP 2.021), and this substance 'is form and content' (TLP 2.025).

Of an object’s form Wittgenstein asserts:

The possibility of its occurring in states of affairs is the form of an object. (TLP 2.0141)

This possibility is internal to the object:

[I]f a thing can occur in a state of affairs, the possibility of the state of affairs must be written into the thing itself. (TLP 2.012)

Indeed it exhausts the object's internal nature:

If two objects have the same logical form, the only distinction between them, apart from their external properties, is that they are different. (TLP 2.0233)

And we may infer that this distinction between two objects of the same form will consist in a difference of content. An object is a form and a content; two objects of the same form will thus be two and not 
one by virtue of a difference of content. (Two objects, Wittgenstein insists, might even be indistinguishable externally as well as internally (TLP 2.02331, 5.5302).) An object's form is its inner nature and its content, we could say, is its particularity.

This conclusion holds more generally. The substance of the world is constituted by the objects (TLP 2.021) which contain the possibility of all situations (TLP 2.014): what form and content holds to a situation will be of a piece with the form and content of objects. If an object were switched within a situation for another of the same form, then the resulting situation would be identical in form but non-identical in content with the original situation. The general thought will thus be that the form of a worldly element (object, state of affairs, fact, situation) is be its inner, logical nature and its content its particularity.

\section{4}

Strictly speaking, we have seen, only names have meaning (Bedeutung), and we shall rewrite the (general) thesis that a symbol does not determine its meaning as the thesis that a symbol does not determine its semantic value. Our concern with this thesis issuing from the fact that symbols include propositions will then be that one might well think it essential to a proposition that it represents the situation it does. If two propositions represent different situations then they are different propositions. Addressing this concern, we may start with the following remark:

A proposition communicates a situation to us, and so it must be essentially connected with the situation. (TLP 4.03)

A proposition is essentially connected with the situation it represents. Wittgenstein continues:

And this connection is precisely that it is its logical picture. (TLP 4.03)

The essential connection between a proposition and its sense lies in the fact that the one is a logical picture of the other. But what is involved in that?

Looking back in the Tractatus, we find:

If a fact is to be a picture, it must have something in common with what it depicts.

There must be something identical in a picture and what it depicts, to enable the one to be a picture of the other at all. (TLP 2.16-2.161)

What any picture, of whatever form, must have in common with reality, in order to be able to depict it - correctly of incorrectly - in any way at all, is logical form, i.e. the form of reality. (TLP 2.18)

That a proposition is a logical picture of a situation entails that the proposition and the situation share a logical form.

Now as we have seen it is a matter internal to a situation that it has the logical form it does. Equally, we should note, a symbol bears its logical form internally. Wittgenstein is quite clear that a sign does not by itself determine a form:

A sign does not determine a logical form unless it is taken together with its logico-syntactic employment. (TLP 3.327)

Only together with their syntactic use do [name signs] signalise one particular logical form. (NB p53)

It is a necessary condition for the determination of a form that the sign be considered together with its syntactic employment. More, this condition is sufficient:

We have become clear, then, that names may and do stand for the most various forms, and that it is only the syntactical application that signalises the form that is to be presented. (NB p59)

Considered together with its syntactic application, a sign determines a form. A symbol, this is to say, determines a form. Thus the connection between a proposition and its sense that is the sharing of a logical form will be an internal connection. This point holds for symbols generally: 
The point is only that the logical part of what is signified should be completely determined just by the logical part of the sign and the mode of signification [Bezeichnungsweise]: sign and mode of signification together must be logically identical with what is signified. (NB $\mathrm{p} 19)$

What I now want further to assert is that this identity of logical form exhausts the internal connection between the symbol and its semantic value: all other (relevant) connections are external. Consider as an appetiser for this Wittgenstein's remark made immediately on introducing the idea of a picture:

Pictorial form is the possibility that things are related to one another in the same way as the elements of the picture.

That is how a picture is attached to reality; it reaches up to it [es reicht bis zu ihr]. (TLP 2.151-2.1511)

A picture shares a form with the reality it represents; that is how the two are internally attached. Thus Wittgenstein comments in Some Remarks on Logical Form:

I have said elsewhere that a proposition "reaches up to reality", and by this I meant that the forms of the entities are contained in the form of the proposition which is about those entities. (PO p34)

Next we can note Wittgenstein's assertion that:

A picture can depict any reality whose form it has. (TLP 2.171)

Immediately after saying that it is necessary for a picture to have a certain sense that the two, picture and situation, share a form, Wittgenstein proceeds to claim that the meeting of this condition is sufficient for the possibility of this depiction. A proposition can depict any reality whose form it has: it is internally suited to represent any such situation. A proposition will not, therefore, determine its sense as such: matters external to the proposition being otherwise it could have had some other sense of the same form.

Now if this is to be so - if a proposition is to contain, or determine, ${ }^{5}$ the form of its sense but is not to determine its sense - it must be, recalling Wittgenstein's dualism of form and content, that a proposition does not contain the content of its sense. And so we find:

A proposition contains the form, but not the content, of its sense. (TLP 3.13)

A proposition and its sense stand in the internal relation of formal identity; external to a proposition, however, is the content of its sense. And recalling further that the dualism of form and content is that of nature and particularity, we can express this by saying that a proposition determines the inner nature but not the particularity of its sense. It determines the type but not the token. A proposition contains the inner nature of the situation which is its sense, and thereby the possibility of representing it (being of the same form as a situation is, we have seen, the only condition on the proposition itself for it to represent that situation), but it does not contain that particular situation which is its sense:

[W]hat represents is not merely the sign or picture but also the mode of representation. ... Then - picture and mode of representation are completely outside what is represented! (NB p21)

A proposition, therefore, does not actually contain its sense, but does contain the possibility of expressing it. (TLP 3.13)

By distinguishing a particular situation from its form, we deny a tension amongst the assertions that a symbol does not determine its semantic value, that a proposition is a symbol, that a proposition's semantic value is the situation it represents, and that a proposition is essentially connected with the situation it represents. A proposition is essentially connected with the situation it represents in that it contains, or shares, its form. This determination does not amount, however, to the determination of the very situation itself, for to determine a logical nature is not to determine a bearer 
of that nature. Two non-identical situations may be of the same form; which, if either, of those two is represented by some proposition of that form would be a matter external to the proposition itself. At the start of this section we mooted, as a counterexample to the thesis that a symbol does not determine its semantic value, that it would be internal to a Wittgensteinian proposition that it represents what it does. We have found that this is not in fact the case.

As might be expected, these results generalise across symbols other than propositions. Wittgenstein writes at Tractatus 3.341:

So what is essential in a proposition is what all propositions that can express the same sense have in common.

And similarly, in general, what is essential in a symbol is what all symbols that can serve the same purpose have in common. (TLP 3.341)

What is essential in a proposition is not what all propositions that express the same sense have in common - namely, its sense - but rather what all propositions that can express the same sense have in common - namely, the form of its sense. And generally, what is essential in a symbol is what all symbols have in common that can, and not $d o$, serve the same purpose. For example, what is essential to a name is what all names that can stand for its referent have in common, and this is the form of that object. A name can stand for any object whose form it has: it contains the form, but not the content, of its referent. $^{6}$

It has been argued in this first section that Wittgenstein considers language at three different levels: at the level of perceptible elements (signs), at the level of syntactic elements (symbols) and at the level of semantically significant elements (symbols together with their semantic values). ${ }^{7}$ Syntactic elements are perceptible elements together with a mode of signification (a syntactic employment), and semantically significant elements are syntactic elements together with a semantic value. A sign does not by itself determine a logical form; a symbol, which includes a logical form and is the (potential) meaning bearer, does not by itself determine a semantic value. ${ }^{8}$

\section{Nonsense}

\section{1}

Closely connected in the Tractatus to Wittgenstein's distinction between sign and symbol is a discussion of the nature of nonsense. This discussion will be the object of investigation of the second section of this paper. We can begin by introducing some examples of would-be nonsense propositions. Wittgenstein's example in the Tractatus of a would-be nonsense proposition is 'Socrates is identical' (TLP 5.573, 5.5733). Working with the Russellian categories of particular, property, dual relation etc., one might naturally (perhaps) say that 'Socrates is identical' predicates identity of Socrates and that this is nonsense because identity is a relation and not a property. In his Notebooks Wittgenstein uses instead the example 'Socrates is Plato' and a comparable thought will go here. 'Socrates is Plato', one might think, predicates Plato of Socrates, but this is nonsense because Plato is a particular and not a property. ${ }^{9}$ (In indicating these reasonings about 'Socrates is identical' and 'Socrates is Plato' I do not mean to suggest that the Tractarian Wittgenstein subscribes to the Russellian logical categories of entity (the categories particular, property etc.): he does not. I shall, however, suggest that in his examples 'Socrates is identical' and 'Socrates is Plato' Wittgenstein is exploiting the Russellian system. Wittgenstein envisages an interlocutor who, given 'Socrates is identical', reasons with the Russellian categories in the manner just considered. ${ }^{10}$ )

We may also work up an example of a would be nonsense proposition, necessarily more abstract, in purely Tractarian terms. A Tractarian elementary proposition consists of names combined together in a certain way, and what it asserts is that the entities its names stand for are themselves combined in that same way (TLP $2.1 \mathrm{ff}$.). Now we have seen that an entity's combinability with other entities is its form. So suppose that $\mathrm{m}$ is a manner in which an object of form $\mathrm{f} 1$ may combine with an object of form $\mathrm{f} 2$ to make a state of affairs. And let $\mathrm{n} 1$ be a name of an object o1 of form $\mathrm{f} 1$ and $\mathrm{n} 2 \mathrm{a}$ name of an object o 2 of form $\mathrm{f} 2$. Then the combination of $\mathrm{n} 1$ and $\mathrm{n} 2$ in manner $\mathrm{m}$ will be an elementary proposition representing that 01 and $o 2$ are combined in manner m. Further, let's suppose that there are also objects of form f3, distinct from $\mathrm{f} 1$ and $\mathrm{f} 2$, and that an object of form $\mathrm{f} 1$ cannot combine in manner m with a object of form $\mathrm{f} 3$ : there is no such thing as that - the objects don't go together in that way. ${ }^{11}$ What, though, if we were to take the name $n 1$ of object o1 and combine it in manner $m$ with a name $n 3$ of an object 03 of form $f 3$ ? We would seem at this point to have a nonsense representation that 01 and 03 are combined in manner m. Just as in Russell's system Socrates and 
identity cannot combine as subject and predicate (identity is not a property), and so the proposition 'Socrates is identical' which asserts that they are so combined is a nonsense proposition, so in our abstract Tractarian example o1 and o3 cannot combine in manner m (o3 does not have an appropriate form), and the proposition NP consisting of $n 1$ and $n 3$ combined in manner m which asserts that they are so combined is a nonsense proposition.

\section{2}

Plausible as these ideas of NP and 'Socrates is identical' as representations of nonsense might be, Wittgenstein considers them to be sorely amiss. 'Thought', he insists, 'could never be of anything illogical' (TLP 3.03). We cannot represent an illogical state of affairs, such as Socrates and identity combining as subject and predicate or o1 and o3 combining in manner m. But why not?

Investigating NP a little more carefully, we may remind ourselves that names n1, n2 and n3 are symbols rather than (mere) signs, and that as such they will have a form. Further, we can note that their forms will be $\mathrm{f1}, \mathrm{f} 2$ and $\mathrm{f} 3$ respectively: it is a condition on a symbol's having a certain semantic value that it share a form with that value. Now the form of a name, as that of an object, will be a matter of its combinability: as an object's form is its combinability with other objects to make states of affairs, so a name's form will be its combinability with other names to make (legitimate) elementary propositions. Thus as objects of form $\mathrm{f} 1$ can combine in mode $\mathrm{m}$ with objects of form $\mathrm{f} 2 \mathrm{but}$ not objects of form $\mathrm{f} 3$ to make states of affairs, similarly names of forms $\mathrm{f} 1$ can combine in mode m with names of form $\mathrm{f} 2$ but not names of form $\mathrm{f} 3$ to make (legitimate) elementary propositions. NP, we may however recall, was to be precisely the combination in mode $\mathrm{m}$ of a name $\mathrm{n} 1$ of form $\mathrm{f} 1$ with a name $\mathrm{n} 3$ of form f3. NP would therefore be an illegitimate construction, an illogical construction: within it, names are to combine in a manner which goes against their forms. As conceived, then, NP would not only be a nonsense proposition in that it represents a nonsense (represents that objects are combined together in a manner in which it is not logically possible for them to combine), but it would also, as a condition of its making its nonsense representation, itself have to be illegitimately, or illogically, constructed.

The result here is quite general. Wittgenstein's theories of representation, specifically the insistence that in order for a name to stand for an object it must have that object's form and the thesis that objects are represented as combined in a certain way by having their names combined in that same way, mean that what could represent objects as combined in a manner to which they are logically unsuited would have to be composed of names combined in a manner to which they themselves are logically unsuited. A representation and what it represents must share a logical form, and so if the latter is to be illogical so also must be the former.

Returning now to the question of why we cannot represent a logical nonsense, Wittgenstein explains his position as follows:

Thought could never be of anything illogical, since, if it were, we should have to think illogically. (TLP 3.03)

We cannot represent something illogical in thought or language, for that would require the representing thought or proposition itself to be illogical. And this requirement, Wittgenstein maintains, cannot be met:

[T]he impossibility of illogical thought (TLP 5.4731)

[A]ny possible proposition is legitimately constructed (TLP 5.4733)

Symbols cannot be illegitimately combined, cannot be combined in a way which goes against their forms. What is constructible in language or thought (in symbols) is also legitimate:

Whatever is possible in logic is also permitted (TLP 5.473)

And from this it follows, given a coincidence of logical form between a symbol and its meaning, that:

[L]anguage itself prevents every logical mistake. (TLP 5.4731)

Language is such that illogical propositions are not constructible, and this means that we cannot make a logical mistake, we cannot represent what is logically impossible. ${ }^{12}$ 
Wittgenstein's assertion that it is impossible to represent a logical nonsense is backed first by his theory that this would require the representing symbol itself to be illogical, and second by the claim that illogical symbols are ruled out. But why, we can now ask, should there not be an illogical symbol?

$\mathrm{NP}$ is, as proposed, an illogical symbol. Something we can note straightaway, however, is that its possibility is not obvious. NP is to be constructed by taking two names and combining them together in a certain manner. The names which are to be put together are, we should however recall, symbols and not (merely) signs. Certainly we may combine signs however we like on a page. And certainly symbols do very often occur combined together when we make such sign combinations. But this does not mean that we can combine symbols in any way we please simply by combining their signs on a page. There is no immediate reason to think it sufficient for the occurrence of a combination of the symbols 'Socrates' and 'identical' occurring in the propositions 'Socrates is dead' and 'Hesperus is identical to Phosphorus' respectively that we write the sign 'Socrates is identical' on the page.

Symbols are signs together with a logical form, but the two are not magically glued together: there is no guarantee that wherever a sign occurs it will bear a certain logical form. We should not therefore think that illogical propositions (illegitimate symbols) could be brazenly constructed merely by putting certain signs together in certain ways. Still, though, might there not be some background (of mental acts, perhaps) against which writing the sign 'Socrates is identical' will make for the occurrence of an ill-formed proposition? On what basis does Wittgenstein holds that there could never be an illogical proposition?

Well let's look at the Russellian framework. In this context an illogical proposition might consist, say, in the combination of a proper name and a relational expression in that way in which a proper name and a predicate expression are combined in a subject-predicate proposition. But what mode of combination is that? Well it is a syntactic mode of combination. More specifically, it is, essentially, the combination of expressions as subject and predicate. The mooted illogical proposition would thus be the combination as subject and predicate of a name and a relational expression. Now this should raise an eyebrow. How, we might for instance ask, could we recognise such a syntactic mistake? It would have to be in this way. We are presented with a propositional sign (the perceptible aspect of the illogical proposition), and we discern in that sign the occurrence of two expressions (symbols, syntactic elements) combined as subject and predicate, only we find also that the expression combined as predicate is in fact not a predicate but is rather, syntactically, a relational expression. But this scenario, it is crucial to see, is incoherent. To find two expressions combined as subject and predicate is to find a subject expression combined with a predicate expression. To find an expression combined as a predicate, as a proper name, as a relational expression etc., is to find a predicate, a name, a relational expression etc.. ${ }^{13}$ The syntactic way in which we find syntactic elements to be combined in a certain proposition is not separable from the syntactic elements we find there. And the point is of course not (merely) epistemic. We can find syntactic entities combined together in any way in which it is possible for them to occur combined. What syntactic types there are combined at some point is not separable from the manner there of their combination: indeed, it is contained in the manner there of their combination. ${ }^{14,15}$

$\mathrm{NP}$, we therefore conclude, will not be a possibility. Its idea is a confusion. As in the Russellian system there could be no such thing as the combination as subject and predicate of what is not a subject expression and a predicate expression, so in our Tractarian terms introduced above there could be no such thing as the combination in manner $\mathrm{m}$ of what is not an expression of form $\mathrm{f} 1$ and an expression of form $\mathrm{f} 2$.

\section{3}

Writing 'Socrates is identical' will not in any context make for the representation of a logical nonsense. In order to represent a nonsense we would need an illogical symbol, but it is in the nature of symbols that such a thing could not exist. (In order to represent that Socrates is combined with identity as subject and predicate (in order to predicate identity of Socrates), we should need a proposition in which a relational expression combined as a predicate expression: but this is a contradiction.) Wittgenstein's response to the example does not however stop here. He offers us further both a diagnosis of the mistake which might lead one to think that 'Socrates is identical' represents a nonsense and also an account of what he considers actually to be going on with this sentence. Let's take the second of these first.

At Tractatus 5.4733 we find:

Frege says that any legitimately constructed proposition must have a sense. And I say that any possible proposition is legitimately constructed, and, if it has no sense, that can only be because we have failed to give a meaning to some of its constituents. (TLP 5.4733) 
'Any possible proposition is legitimately constructed': this we have seen. Wittgenstein continues, however, with: 'and if it has no sense, that can only be because we have failed to give a meaning to some of its constituents'. ${ }^{16}$ According to Wittgenstein, Frege thought that it was sufficient for a proposition to have a sense that it be legitimately constructed. In response, Wittgenstein (implicitly) criticises Frege for thinking that there might be an illegitimately constructed proposition, and then proceeds to deny that a (legitimately constructed) proposition must have a sense. A proposition may fail to have a sense by virtue of the failure of one of its constituents to have a meaning. Applying this to the example 'Socrates is identical', Wittgenstein then asserts:

Thus the reason why 'Socrates is identical' says nothing [sagt nichts] is that we have given no meaning to the word 'identical' as adjective. (TLP 5.4733)

The reason why 'Socrates is identical' means nothing [heißt nichts] is that there is no property called 'identical'. The proposition is senseless [unsinnig] because we have failed to make an arbitrary determination and not because the symbol, in itself, would be illegitimate. (TLP 5.473)

We may consider ourselves to have with 'Socrates is identical' a perfectly legitimate proposition, only one that is senseless on account of the fact that one of its constituents has not been given a meaning. ${ }^{17}$ Borrowing from the Russellian stock of propositional forms and entity types, we may suppose 'Socrates is identical' to be a perfectly good subject-predicate proposition - 'Socrates' is a perfectly good proper name and 'is identical' is a perfectly good predicate - but whilst the proper name symbol 'Socrates' has been given a meaning, the predicate symbol 'is identical' has not. There is no property called 'identical': as adjective, 'identical' does not have a meaning.

Wittgenstein's thought here bears repetition. We are presented with a sign, say 'Socrates is identical'. To make sense of it we first locate there a syntactic structure: we find it to be the sign of a propositional symbol (a proposition). Subsequently we look to see whether the syntactic components which compose the discerned proposition are meaningful or not. If they are then the proposition has a sense. But the syntactic components may not all be meaningful and if they are not, this entails that the proposition is senseless. What it does not (necessarily) entail, however, is that we should reassess our finding the proposition we did. Wittgenstein holds that the propriety, when given a sign, of locating there a certain symbol is not dependent upon the located symbol being semantically significant. 'Socrates is identical' may be the sign of a perfectly good subject-predicate proposition (propositional symbol) despite the fact that the adjectival symbol 'identical' contained in that proposition - the word 'identical' appearing (used) there as adjective - has no meaning. ${ }^{18,19}$ (A picture of two people next to each other may be just that even if one of the figures fails to represent anyone.)

Let's assess now what was wrong with the reasoning behind the idea that 'Socrates is identical' represents a nonsense. The thought was that 'Socrates is identical' is nonsense because it predicates identity of Socrates and identity is a relation and not a property. 'Socrates' means Socrates, 'identical' means identity, and the proposition is of the subject-predicate form. Wittgenstein, we can however see, will find here an insensitivity to the sign-symbol distinction. Once it is noted that it is symbols and not signs which are the (primary) bearers of semantic significance we will find ourselves with no reason to suppose that the symbol 'identical' appearing in 'Socrates is identical' means identity. If 'Socrates is identical' is to be a subject-predicate proposition, then its component symbol 'identical' will have to be an adjectival symbol. The standard English symbol 'identical' meaning identity - the symbol 'identical' in 'Hesperus and Phosphorus are identical' - is however a relational symbol. As such, this English symbol is a different symbol from 'identical' in 'Socrates is identical' (a symbol's syntactic nature is essential to it). Why then, we might now ask, should we suppose that the two have a common meaning? Certainly they share a sign, but this is hardly sufficient to presume a shared meaning (Mr Green's name shares a sign with a colour word, but this does nothing to suggest that the two symbols share also a meaning):

Thus the reason why 'Socrates is identical' says nothing is that we have given no meaning to the word 'identical' as adjective. For when it appears as a sign for identity, it symbolises in an entirely different way - the signifying relation is a different one: the two symbols have only the sign in common, and that is an accident. (TLP 5.4733)

When 'identical' appears as a sign for identity (as in, say, 'Hesperus and Phosphorus are identical') its mode of signification is quite different from that found in 'Socrates is identical'. The two signs thus 
belong to quite different symbols, and when this is seen we lose all reason for supposing that they have the same meaning.

More, let's finally repeat, Wittgenstein holds that a symbol and its meaning must share a form, and from this it follows that the 'identical' of 'Socrates is identical' could not mean identity. The former is an adjective and the latter a relation. Generally, Wittgenstein’s insistence of an identity of form between a symbol and any semantic value it can have rules out, given the impossibility of an illformed propositions, the representation of a logical nonsense. ${ }^{20}$ A proposition (propositional symbol) may be nonsense in that it lacks a sense (fails to represent a situation) - and this will be so just in case it has a meaningless part - but it may not be nonsense in that it has a logically impossible sense. The proposition (propositional symbol) 'Socrates is identical' does not represent a nonsense on account of what 'identical' means (that is, on account of its meaning a relation): rather it lacks a sense because no meaning has been given to its component adjectival symbol 'identical'.

\section{The Context Principle}

\section{1}

My account of the Tractarian position on nonsense is in close agreement with that given by Cora Diamond in her paper Throwing Away the Ladder. She writes there:

[Wittgenstein] says at 5.4733 that any possible sentence is, as far as its construction goes, legitimately put together, and, if it has no sense, this can only be because we have failed to give a meaning to some of its constituents, even if we think that we have done so. Thus the reason why "Socrates is identical" says nothing is that we have not given any adjectival meaning to the word "identical." The word "identical” as it occurs in (e.g.) "The morning star is identical with the evening star" is, syntactically, a totally different symbol from what we have in "Socrates is identical." So the sentence "Socrates is identical" is legitimately put together, in the sense in which "Socrates is frabble" is, as far as syntactic structure goes, legitimately put together. Both contain what are syntactically adjectives; all they need is for some adjectival meaning to be fixed for them. What I am emphasising is that on Wittgenstein's view, the only thing wrong with "Socrates is identical" is the absence of an adjectival meaning for "identical," where the need for a meaning may be hidden from us by the fact that the word "identical" has other uses in which it is meaningful. (Diamond 1991: 196-197)

In this passage Diamond makes a clear distinction between syntax and meaning, and she expressly allows that a sign might occur with a syntax but without a meaning. 'Frabble' as it appears in 'Socrates is frabble' is syntactically an adjective, but it does not there mean anything. This position is a move away from that discussed in an earlier paper of hers, What Nonsense Might Be:

I assume there are two kinds of general rule, one kind enabling us to break down whole sentences into elements with a syntactic characterization, and another sort fixing the meanings of proper names, concept expressions and relational expressions of various sorts; neither kind of rule will apply unconditionally to a given sentence. Take as an example a sentence like one Frege uses: "Venus is more massive that Mercury." We can, using the general rules of English, characterize the structure of the sentence, but any such characterization will apply to the sentence only conditionally. Thus the sentence may be taken to be a two-term relational expression completed by the proper name "Venus" in the left-hand place and the proper name "Mercury" in the right hand place, but only if the thought expressed by the whole sentence is that the object "Venus" stands for, has whatever relation it is the relational expression stands for to whatever object it is "Mercury" stands for. (Diamond 1991: 109-110)

Here we still have the syntactic-semantic distinction in play, but the two factors are more tightly bonded together. We may consider a sentence to have a certain syntactic structure - we may consider it composed in a certain way of certain syntactic elements - only if the sentence, so construed, is semantically significant (only if it expresses a thought).

In What Nonsense Might Be Diamond presents this latter position as the 'Frege-Wittgenstein view' of nonsense. Frege is, however, much the more discussed of the two and the position is more 
plausibly ascribed to him than to Wittgenstein. Frege does appear to hold that in order to find syntax we must at the same time find semantics. So for instance he wrote in The Foundations of Arithmetic:

Nevertheless, there is something to prevent us from regarding (2-3) without more ado as a symbol which solves the problem; for an empty symbol is precisely no solution; without some content it is merely ink or print on paper. (Frege 1980: §95)

And later on, when his distinction of sense and reference is in play, he asserts:

A proper name must at least have a sense [if not a referent]; otherwise it would be an empty sequence of sounds and it would be wrong to call it a name. (Frege 1997: 180)

In the absence of semantic significance, Frege insists, we are left not with a meaningless syntactic element but rather with a mere sign: with ink or print on paper, or a sequence of sounds. ${ }^{21}$ Language, the idea would seem to be, is an essentially semantic affair: syntax is a matter of logical similarities and differences (themselves essential, of course) across what are essentially semantic elements.

Now it is interesting for us further to see that Frege's tying together of syntax and semantics was presented by Diamond in a very particular way. She did not write that 'Venus is more massive than Mercury' may be considered to contain a proper name 'Venus' only if 'Venus' is actually the proper name of some object. Rather her suggestion was that we may find 'Venus is more massive than Mercury' to contain a proper name 'Venus' only if the sentence as a whole may be found to express a thought about some object called 'Venus'. More generally, she asserts that:

Taking the rules which fix the meaning of expressions in the language to apply to the particular sentence is not separable from making sense of the whole sentence. (Diamond 1991: 110)

We may take the rules which fix the meaning of expressions in the language to apply to a particular word only if that word is a constituent of a sentence of which we are successfully making sense. We may locate syntax only where we may locate semantics, and we may locate semantics only within the expression of a thought.

Diamond takes this latter to be the gist, or at least a key rub, of Frege's context principle:

[W]e ought always to keep before our eyes a complete proposition. Only in a proposition have the words really a meaning. (Frege 1980: §60)

I shall not, however, get involved here in Frege exegesis. Rather, the point will be to compare two apparently Fregean theses with the ideas of the Tractatus. ${ }^{22}$ The first (apparently) Fregean thesis is that what has a syntactic character is something essentially semantic, something of whose essence it is that it means what it does. Contrasting with this, I have argued, is the Tractarian idea of a symbol. A Tractarian symbol is a syntactic entity but it carries what semantic significance it has only inessentially. A Tractarian symbol may mean anything whose form it has and indeed it may mean nothing at all. The second (apparently) Fregean thesis is that the (Fregean) semantico-syntactic elements of language occur only within occurrences of propositions. To compare this with the Tractatus is our next task.

\section{2}

Let's consider a remark of Wittgenstein's which might appear to go against the idea that there could be a semantically insignificant symbol. At Tractatus 3.326 Wittgenstein writes:

In order to recognise a symbol by its sign we must observe how it is used with a sense.

(TLP 3.326)

If 'with a sense' is taken here to mean 'with semantic significance' then the possibility of a semantically insignificant symbol would be at risk: such a thing would be unrecognisable. How else, though, might one take the expression? Well, Wittgenstein's German has it that it is the sinnvolle Gebrauch that we must consider, which Ogden translates as the 'significant use'. This rendering was sanctioned by Wittgenstein himself, who explains the section to Ogden as follows:

I think "significant" is alright here. The meaning of the prop is: that in order to recognise the symbol in a sign we must look at how this sign is used significantly in propositions. I.e. 
we must observe how the sign is used in accordance with the laws of logical syntax. Thus “significant” here means as much as "syntactically correct”. (LO p59)

With this explanation the threat to the possibility of a semantically insignificant symbol is removed. What we must observe in order to recognise a symbol in a sign is not the semantically significant use but rather the syntactic use. Sinnvoll here means syntactic. ${ }^{23}$ What I want to note looking forward, however, is Wittgenstein's comment in his letter that the use of a sign 'in accordance with the laws of logical syntax' is a use of it 'in propositions'.

The idea that it is in propositions that signs 'have sense' emerges also in an explanation given by Wittgenstein in 1930 of the first section of his Tractatus:

1. "The world is everything that is the case". This is intended to recall and correct the statement "The world is everything that there is"; the world does not consist of a catalogue of things and facts about them (like the catalogue of a show). For, 1.1, "The world is the totality of facts and not of things”. What the world is is given by description and not by a list of objects. So words have no sense except in propositions, and the proposition is the unit of language. (LWL p119)

The unit of the world, we are told, is not the thing but the fact. Things (objects) partake in the world only from within facts and not by themselves. And similarly, Wittgenstein says, words have no sense except in propositions, which are the units of language. What notion, though, of 'having sense' does Wittgenstein intend at this juncture? If we take ‘have sense' here to mean 'represent a situation' then Wittgenstein's assertion is that it is only in propositions that words (are used to) represent situations. This is of course true, but it is hard to see either how it is non-trivial or how it might mean (or be meant by) a thesis that the proposition is the unit of language. If, however, we take 'have sense' here to mean what was meant at Tractatus 3.326 by being in sinnvollen Gebrauch, namely being in syntactic use, then what Wittgenstein presents in this retrospective remark of 1930 is the thesis that words are without syntactic character except as they figure in propositions. This is the reading I want to recommend.

Wittgenstein holds that as the unit of the world is the fact and not the thing, so the unit of syntax is the proposition and not the name. Signs are in syntactic use only within propositions: the logico-syntactic use of a sign, the use of a sign as the sign of a symbol, is a use essentially within propositions. As things (objects) occur in the world only within facts, so syntactic elements - symbols - occur in language only within propositions.

There are a number of paths to and from this important crux of Wittgenstein's thought. ${ }^{24}$ Here I can discuss only a couple of its easy consequences. One consequence worth noting as such is the idea discussed above that there can be no illogical proposition. An illogical proposition, such as NP, was to be an illegitimate combination of sub-propositional symbols. But if there are sub-propositional symbols - sub-propositional logical elements as opposed to mere signs - only within what is already a proposition, then there can be no such illegitimate construction. There can be nothing illegitimate in logic (syntax), for there is logic (syntax) only within what is already legitimate. I argued above that a sub-propositional symbol may be found combining only as the symbol it is (that is, legitimately); the current, stronger thesis is that is that it is only in propositional (and so legitimate) combination that subpropositional symbols are to be found. ${ }^{25}$

A second consequence, equally easy to draw, is that there is semantic significance only in the context of a proposition. As it is symbols and not signs which are in the first instance semantically significant (what represents and what is represented must share a logical form), it follows from the thesis that symbols occur only within occurrences of propositions that there can be semantic significance only within a proposition. It is only in the context of a proposition that a sign may occur as the sign of a symbol, and so it is only there that a sign may be semantically significant.

At Tractatus 3.3 Wittgenstein writes:

Only propositions have sense; only in the nexus of a proposition does a name have meaning. (TLP 3.3)

Only propositions have a syntax: it is only within propositions that syntax is to be found. Thus it is only in the nexus of a proposition that a name-sign may be the sign of a name-symbol and so have a meaning. ${ }^{26}$

Once Wittgenstein has introduced his notion of a symbol and thus loosed the notions (apparently) tied together in Frege of syntax and semantics, then the (apparent) Fregean thesis that the semantico-syntactic unit is the proposition cannot continue unmodified. I have suggested that the 
descendent principle adopted by Wittgenstein, whilst it has consequences regarding the location of semantics, is concerned in the first instance with syntax only. The syntactic unit, Wittgenstein asserts, is the proposition. A Wittgensteinian symbol is a sign considered together with a logico-syntactic use and Wittgenstein's context principle characterises that use as a use essentially within propositions. ${ }^{27}$

\section{Realism}

\section{1}

David Pears has defended an interpretation of the Tractatus on which, as he puts it, 'language is shaped by the intrinsic nature of the underlying simple objects' (Pears 1987: 13). Using 'name' to refer to a name-sign rather than a name-symbol, he writes:

Once a name has been attached to an object, the nature of the object takes over and controls the logical behaviour of the name, causing it to make sense in some sentential contexts but not in others. (Pears 1987: 88)

In a similar vein, Norman Malcolm writes in Language and the Objects:

According to the Tractatus, the syntax of a name will indeed match the form of the object that the name means. But the name has that particular syntax because of the nature of the object for which it deputizes. The syntax of the name is derived from the object. Having that syntax is not what 'meaning that object' comes to. (Malcolm 1986: 27)

Malcolm's last remark here is targeted at Peter Winch's assertion that a name's 'having the meaning it does just consists in its 'significant use' (sinnvollen Gebrauch)' (Winch 1987: 9). Winch continues:

Proposition 3.334 reads: 'The rules of logical syntax must go without saying, once we know how each individual sign signifies.' It is important that Wittgenstein writes wie ('how') rather than was ('what'). The what will already have been settled once the how is established. (Winch 1987: 9)

And he talks of:

the misunderstanding of supposing that a name's meaning is something other than and prior to its logico-syntactic role. (Winch 1987: 10)

It should be clear that I am going to oppose myself to both of these positions. Pears and Malcolm suggest that a name-sign derives its logical behaviour, its syntax, from its meaning (the object it stands for). I have argued, however, a sign may be given a meaning only as it is already in syntactic use, only as it is already the sign of a symbol. Indeed, Pears and Malcolm would have a Tractarian symbol bear what is essential to it - its form - by virtue of what is inessential to it - its content. No more palatable than the Pears-Malcolm position, however, is Winch's contrasting suggestion that we may identify a name's meaning with its logico-syntactic role. The logico-syntactic employment of a sign determines a form but it does not determine a content. ${ }^{28}$ A sign in syntactic use as a name of a certain form may stand for any object of that form. Meaning does not collapse into logico-syntactic use; content does not reduce to form. Neither is it the case that a sign's logical use derives from its contact with reality, and nor is it the case that reality is immanent in signs in logical use.

Winch is by no means a lone figure of Tractatus scholarship in his emphasis on the importance of a sign's use in the determination of its meaning. In 1969 Hidé Ishiguro wrote:

The interesting question, I think, is whether the meaning of a name can be secured independently of its use in propositions by some method which links it to an object, as many, including Russell, have thought, or whether the identity of the object referred to is only settled by the use of the name in a set of propositions. If the latter holds, then the problem of the object a name denotes $i$ s the problem of the use of the name.

Contrary to widespread belief, Wittgenstein rejected the former view throughout his writings and tried to work out various versions of the second. (Ishiguro 1969: 20-21)

More recently the stance has been adopted by James Conant: 
But the whole point of $\S \S 3.3-3.344$ of the Tractatus is that the identity of the object referred to by a name is only fixed by the use of the name in a set of significant (sinnvolle) propositions. (Conant 2000: 212-3)

Where Winch, however, makes it quite clear that the 'use in propositions' which he takes to be constitutive of meaning is what Wittgenstein calls the logico-syntactic use of signs, Conant would appear to allow that signs in the same logico-syntactic use might yet have different meanings. He asserts in discussion of Wittgenstein's 'Green is green' that in this sentence “"green” can be seen to be not merely ambiguous with respect to its meaning (the way "bank" is in "The bank is on the left bank”), but ambiguous with respect to its logical type' (Conant 2000: 193). Assuming, then, that Conant takes words of the same logical type (for instance the two words 'bank' in 'The bank is on the left bank') to be in the same logico-syntactic use, the question arises of what notion of 'use in propositions' Conant sees as the sole determinant of a name's meaning.

Conant's focus for his answer here is on Tractatus 3.326 where, as we have seen, Wittgenstein says that in order to recognise the symbol in the sign we must consider the sinnvollen Gebrauch. Instead, however, of noting Wittgenstein's letter to Ogden in which the sinnvollen Gebrauch is explained as the use 'in accordance with the laws of logical syntax' (LO p59), Conant reads it instead as the use 'in a set of significant (sinnvolle) propositions' where 'in order to count as sinnvoll a Satz ... has to make a statement about how things are' (Conant 2000: 213). The use which is the determinant of meaning for Conant is a use of signs to represent situations. ${ }^{29}$ Now being the unaided means by which an 'orthographic unit' (Conant 2000: 190) becomes a meaningful symbol, this use of signs must at once fix not only semantics but also syntax. More, the use is to be unitary: we cannot hive off an element of it which determines syntax and then a second which determines meaning. What determines syntax, for Conant, at once determines meaning, and vice versa. With these features, however, it becomes difficult to see how Conant's 'use of signs to represent situations' can be made to sit happily with Wittgenstein's notion of logico-syntactic employment. If the two uses are identified then despite what his discussion of 'Green is green' might suggest, Conant's position can differ very little from Winch's and will be subject to the same criticism. Alternatively, if, as Conant's writings suggest, his 'use in a set of significant propositions' is to be distinguished from logico-syntactic employment then the latter would appear to have been made redundant: syntax is constituted elsewhere. More, Conant will in this latter case have introduced a notion of a use of signs which is, so far as I can see, absent from the Tractatus. Scattered throughout the Notebooks and the Tractatus is the idea of a sign's logico-syntactic employment; it is most unclear that Wittgenstein is involved in any further notion of the use of signs.

Unlike Pears and Malcolm, then, Conant does not see form as deriving from content. And unlike Winch he does not appear to reduce content to form. Insofar as he avoids the latter, I would however suggest, he develops a notion of the use of a sign in propositions which is foreign to the Tractatus and which displaces Wittgenstein's notion there of logico-syntactic employment.

Structurally, my position may be contrasted with those of Conant, Winch and Pears and Malcolm on the basic ground that where I see Wittgenstein taking two steps between a name-sign and its meaning they all find only one. Pears and Malcolm take reference to be the one step and suppose that syntactic use will come there in tow. Winch takes syntactic use to be the one step and supposes that reference will come constituted therein. Conant takes there to be a single step of semanticosyntactic use. My suggestion, by contrast, is that syntactic employment is one step, and that there is then the further step of reference.

\section{2}

The account of Pears and Malcolm is obviously describable as a realist one. Signs connect to extralinguistic entities and what combinations of signs make sense is then determined by the intrinsic nature of the entities to which they are connected. Winch, Ishiguro and Conant have seen their use theories of meaning as avoiding such realistic tones. Where in this area of classification, it might be asked, would my story fit? Well I think that what I have said so far might be moved on in a number of directions, some realist, some not so. One way to progress the story would be to take on the issue, so far more or less untouched, of the constitution of reference. Rather than open that can, however, I want to close this paper with a consideration of a rather different kind. There are, I think, some remarks in the texts not directly concerned with the constitution of reference which may be used to support the ascription to Wittgenstein of a realist metaphysic.

I have insisted in contradiction to Pears and Malcolm that signs gain and bear logical forms independently of what meaning they may or may not have. Rather, signs do this - and I've been less 
explicit here - by virtue of the place they occupy within a whole calculus of signs, within an entire syntactic system. There are symbols only within propositions, and what a proposition is is a unit of a syntactic system. ${ }^{30}$ A symbol's form is generated only within a syntactic system. Now if we recall alongside this that a symbol can mean only what shares its form, the thought would appear to be available that it is required of a syntactic system as a whole, if it is to be such as to allow for its elements to be meaningful, that it generate not just any forms but rather logical forms - those forms, that is, which are found independently in reality. In order for its units (propositions) to be appropriate for representation, language as a whole, the realistic thought will be, is required to replicate, in its syntax, the logical structure of reality. ${ }^{31}$

In 1914 Wittgenstein wrote:

In order that you should have a language which can express or say everything that can be said, this language must have certain properties; and when this is the case, that it has them can no longer be said in that language or any language. ...

Thus a language which can express everything mirrors certain properties of the world by these properties which it must have. (NB p108)

Logical form, we are told in the Tractatus, - the form of reality - 'finds reflection in language' (TLP 4.121). And in 1930 Wittgenstein writes:

Grammar is a mirror of reality. Grammar enables us to express true and false propositions; and that it does so tells us something about the world. What can be expressed about the world by grammar being what it is cannot be expressed in a proposition. For this proposition would presuppose its own truth, i.e. presuppose grammar. (LWL pp.9-10)

But grammar is not entirely a matter of arbitrary choice. It must enable us to express the multiplicity of facts, give us the same degree of freedom as do the facts. (LWL p8)

We must be able to do as much with language as can happen in fact. (LWL p8)

Language represents in two ways -

(1) Its propositions represent a state of affairs and are either true or false.

(2) But in order that propositions may be able to represent at all something further is needed which is the same both in language and reality. ... Thought must have the logical form of reality if it is to be thought at all. (LWL p10)

The suggestion will be that grammar is non-autonomous for the early Wittgenstein. In order to allow for representation, a sign system must be such as to match the logical forms of reality, it must 'give us the same degree of freedom as do the facts'. ${ }^{32}$ Language (grammar) and reality are independently constituted and the former must match the latter, must be in harmony with the latter, if its units are to be capable of representation. . $^{34}$

\author{
Colin Johnston \\ Institute of Philosophy \\ School of Advanced Study \\ University of London \\ Senate House \\ London WC1E 7HU \\ UK \\ colin.johnston@sas.ac.uk
}

\footnotetext{
${ }^{1}$ The following alternative reading of this section is also possible. Wittgenstein holds that difference of meaning entails difference of symbol and is instructing someone (an interlocutor) who is envisaged as not realising this. (Cf. To a struggling maths student: 'These sets do not merely have different members: they are different sets'. Or to a struggling student of Frege: 'These words do not merely
} 
have different referents: they have different senses’.) I think this reading is intrinsically implausible; my rebuttal of it must however be deferred until later in this first section.

${ }^{2}$ To be clear, the point here is best illustrated not by the claim that the symbol 'here' may mean different things on different occasions of its occurrence, but rather by the claim that occurrences of 'The bank is next to the supermarket' and 'The bank is behind the trees' may involve occurrences of the same symbol 'bank' despite reference being made in the former to a financial bank and the latter to a river bank.

${ }^{3}$ I do not mean to suggest any connections here with Dummett.

${ }^{4}$ A quick justification of these introductions may be provided by noting first that a proposition has a sense just in case its constituents have meaning, and second that it is sufficient to understand a proposition that one understand its constituent parts (TLP 4.024). (In particular, it is sufficient to know what situation an elementary proposition represents that one know what its constituent names refer to) (TLP 2.15 etc.).) At Tractatus 5.473 Wittgenstein himself uses the same verb - heißen - to indicate both the saying of a proposition and the meaning of a propositional component.

${ }^{5}$ Wittgenstein moves easily between the terms 'contains' and 'determines' in this context. Thus for instance he writes (as we have seen):

I have said elsewhere that a proposition "reaches up to reality", and by this I meant that the forms of the entities are contained in the form of the proposition which is about these entities. For the sentence, together with the mode of projection which projects reality into the sentence, determines the logical form of the entities. (PO p34)

${ }^{6}$ We can note that if names contained also the content of their referents, then an elementary proposition, which consists of names (TLP 4.22), would contain the content of its sense. Further, if names did not contain the form of their referents, then an elementary proposition would not contain the form of its sense.

${ }^{7}$ Interest is focused in the Tractatus almost exclusively on the middle level, the level of symbols. This is the level at which logic takes grip: a sign does not by itself determine a logical form (TLP 3.327), and matters of meaning are extraneous to logic ('in logical syntax the meaning of a sign should never play a role' (TLP 3.33), 'the rules of logical syntax must go without saying, once we know how [how, not what] each individual sign signifies' (TLP 3.334)).

${ }^{8}$ I shall not in this paper address the question of why Wittgenstein proposes such an account. The answer to this cannot be short and would concern, I suggest, the need for a representation not to stop with what it represents at anything short of a fact (and in particular for it not to stop, as a Russellian judgment, at a mere collection of entities) (PI §95). (See Wittgenstein’s talk at PI §94 of a proposition as an intermediary between the propositional sign and the fact.)

${ }^{9}$ See page 2 of the Notebooks. I take it that Wittgenstein switches his example from 'Socrates is Plato' to 'Socrates is identical' because the former, as much as it might be taken problematically to be predicating Plato of Socrates, might be taken unproblematically to be asserting the identity of Socrates and Plato.

${ }^{10}$ If this seems implausible, we can note that Wittgenstein's non-subscription to the Russellian categories is not the consequence of his subscription to some alternative set, but rather of his position that the ontological variety is not available in advance of the performance of analysis. (See TLP 5.55 5.5571; also PO pp. 29-30 and WWK p 42.) Wittgenstein does not have his own 'a priori' categories to employ, and so he borrows Russell's for the purpose of illustrating a certain family of points.

${ }^{11}$ In fact the latter is entailed by the former: that $\mathrm{f} 3$ is not $\mathrm{f} 2$ means that an object of form $\mathrm{f} 1$ will not combine in manner $\mathrm{m}$ with an object of form $\mathrm{f} 3$. This point will not be pursued directly, though see subsection 2.3 and note 15 below for some relevant discussion.

${ }^{12}$ We can find here with the idea that '[w]hatever is possible in logic is also permitted' (TLP 5.473) (the idea that illogical thought is impossible) the sense for Wittgenstein in which logic 'looks after itself' (TLP 5.473, NB p 4). Whilst a language may have rules for the ways its signs are legitimately to be combined to make propositional signs, there are no rules for how its symbols may legitimately be combined to make propositions: they combine as they can combine and that is all good. There are no laws concerning what is correct and incorrect in logic. (Thus also, logic is a priori not because its laws are self evident, but because acquaintance with a symbol means, in part, knowledge of its combinatorial possibilities (see TLP 5.4731).)

${ }^{13}$ As James Conant puts it:

[T] here are no examples of putting a proper name where a concept word belongs, if one can properly make out that what belongs in that place is a concept word, that that is a sufficient condition for treating whatever is in that place as a concept word. (Conant 2000: 194) 
${ }^{14}$ This line of thought is rather underdeveloped, but hopefully some sense has been conveyed of the key idea in play. A usefully fuller response would demand more space than it is appropriate to assign in this paper.

${ }^{15}$ We can see here why on introducing $\mathrm{f} 3$ as a form distinct from $\mathrm{f} 1$ and $\mathrm{f} 2$ it was unnecessary further to specify that objects of form $\mathrm{f} 3$ could not combine in mode $\mathrm{m}$ with objects of form $\mathrm{f} 1$ (see note 11 above). Similarly, where I wrote above in section 2.1 that: 'in our abstract Tractarian example 01 and o3 cannot be combined in manner $\mathrm{m}$ ( 03 does not have an appropriate form)' I might as well have written in the parentheses: ' $(\mathrm{o} 3 \text { is not of form } \mathrm{f} 2)^{\text {'). }}$

${ }^{16}$ Wittgenstein asserts here that it is sufficient for a proposition to have a sense that its component parts be meaningful. This is also a necessary condition (lack of semantic significance is infectious).

${ }^{17}$ We must of course distinguish the possibility envisaged here of unsinnige propositions from that of tautologies and contradictions which are sinnlos but not unsinnig. The latter possibility lies outside the concerns of this paper.

${ }^{18}$ We should note that this goes beyond the findings of the first section of this paper. It was argued there that what semantic significance a symbol has is a matter external to the symbol (a symbol can mean anything whose form it has), and whilst it sits very naturally with this that a symbol might be without semantic significance, the latter is not entailed by the former. See Tractatus sections 3.13, 4 and 4.5 for further indication that Wittgenstein considers semantically insignificant symbols to be an open possibility.

${ }^{19}$ At Tractatus 4.1272 Wittgenstein envisages the word 'object' being used as a (proper) concept word. Senseless 'pseudo-propositions' (unsinnige Scheinsätze) result, for no meaning has been given to 'object' as a symbol of this kind. Such 'pseudo-propositions', I am suggesting, will despite their senselessness still be propositions. Beside the 5.473's, Wittgenstein talks at several points in his Tractatus of senseless (unsinnig) propositions (see, e.g., 4.003, 6.54) and of propositions containing signs to which no meaning has been given (see 6.53). There is nothing loose or unhappy in such talk. In particular, it is not the case that Wittgenstein should at these points have talked not of propositions but only of propositional signs.

${ }^{20}$ I don't mean to suggest here that the impossibility of representing nonsense is, for Wittgenstein, a result issuing from an independent theoretical commitment to an identity of form between a symbol and its semantic value. I would argue rather that the two ideas amount for Wittgenstein to very much the same thing and represent one of his most basic reflections on the nature of the world and its representation.

${ }^{21}$ For his part, Russell wrote in 1913 that:

So long as the names which I use really are names at the moment, i.e. are naming things to me, so long the things must be objects of which I am aware, since otherwise the words would be meaningless sounds, not names of things. (Russell 1984: 7)

Donna Summerfield, incorrectly as I have argued, claims the same for Wittgenstein:

According to the Tractatus ... no Name can fail to stand in for an object and still be a Name. Without its corresponding object, a Name would be devoid of significance, a meaningless sound or squiggle or mental event. (Summerfield 1996: 119)

${ }^{22}$ My use of the word 'apparently' in this context should not to be taken to indicate suspicion of whether the theses really are Fregean.

${ }^{23}$ Note some further confirmation here of our identification of a symbol as a sign together with its syntactic employment.

${ }^{24}$ These include Frege's saturated-unsaturated distinction and Russell's concerns with the unity of the proposition.

${ }^{25}$ The thesis that the syntactic unit is the proposition is, as said, stronger than the thesis that there can be nothing illegitimate in syntax. The latter could be held whilst the former rejected. It would be a mistake to suppose that Wittgenstein's 'austere' position on nonsense is inseparable from his context principle. It is in part to make this point that I have discussed nonsense before discussing the context principle.

${ }^{26}$ I suggest here that in 3.3 Wittgenstein uses the word 'name' to mean not a simple symbol, but rather the sign of a simple symbol. Wittgenstein does use the word in both ways and is explicit that the names he discusses in the 3.2's are signs and not symbols (see Tractatus 3.202 and 3.26). This use is then carried forward into Tractatus 3.3 .

${ }^{27}$ Having untied syntax and semantics, there is of course space for Wittgenstein to make a further assertion to the effect that the unit semantic achievement is not reference but the representation of a situation (assertion). I do not, however, find Wittgenstein involved in any further such principle. Our apparent Frege asserts that there is meaning only in the context of the expression of a thought: 
Wittgenstein, by contrast I would suggest, allows that the symbol 'Socrates' in 'Socrates is identical' (or in 'Socrates is frabble') may mean Socrates, the philosopher, despite the lack of a meaning there for the adjective 'identical' ('frabble'). A sign may not have a syntax outside the context of a proposition, but it may have a meaning in such a context even if some other element of the proposition is meaningless. A picture of Socrates standing next to someone may be just that even if the figure in the picture next to that of Socrates fails to represent anyone in particular.

${ }^{28}$ Diamond makes this same criticism of Winch's 'formalist' position in Diamond 2006 pp. 158-159.

${ }^{29}$ Conant defines a symbol as 'that which meaningful propositions have in common' (Conant 2000: 190), and by this he intends: that which meaningful propositions have in common as meaningful propositions. (A meaningful proposition (a proposition which represents a situation) contrasts for Conant with tautologies and contradictions and with propositional signs only (Conant 2000: 213-214).) His use of a sign 'in a set of significant propositions' is the use of a sign (an 'orthographic' entity (Conant 2000: 190)) as just such a symbol.

${ }^{30}$ As Wittgenstein later puts it: 'It is only in language that something is a proposition’ (PG p131).

${ }^{31}$ The possibility of this thought depends, of course, on the possibility of making sense of the idea of a variety of non-isomorphic syntactic systems. Whether this can be done in a Tractarian context is open for discussion.

${ }^{32}$ Much of what the later Wittgenstein comes to say of the autonomy of grammar should be understood, the proposal would then be, as a reaction to his early, realistic idea of grammar as responsible to reality.

${ }^{33}$ Diamond would consider this putative non-autonomy a matter of logic's not looking after itself (see Diamond 2006: 152). This may in a sense be correct, but logic's failure here to look after itself would be a quite different failure from that which I read Wittgenstein as ruling out at Tractatus $5.743 \mathrm{ff}$. (see section 2.2 and note 12 above).

${ }^{34}$ This research was conducted whilst holding a Jacobsen Fellowship in Philosophy at the University of London. I am grateful to José Zalabardo and an anonymous referee from European Journal of Philosophy for comments on earlier drafts of this paper.

\section{Abbreviations and References}

\section{Works by Wittgenstein}

LO: Letters to C.K. Ogden, G.H. von Wright ed, Blackwell, Oxford, 1973

LWL: Wittgenstein's Lectures, Cambridge 1930-1932, D. Lee ed, Blackwell, Oxford, 1980

NB: Notebooks 1914-1916, G.H. von Wright and G.E.M. Anscombe eds, Blackwell, Oxford, 1998

PG: Philosophical Grammar, tr. A. Kenny, R. Rhees ed, Blackwell, Oxford, 1974

PI: Philosophical Investigations, tr. G.E.M. Anscombe, Blackwell, Oxford, 1953

PO: Philosophical Occasions, J.C. Klagge and A. Nordmann eds, Hackett, Indianapolis, 1993

PTLP: Prototractatus, tr. D. Pears and B. McGuinness, B. McGuinness, T. Nyberg and G.H. von Wright eds, Routledge, London, 1971

TLP: Tractatus Logico-Philosophicus, tr. Ogden, Routledge, London, 1922, and tr. Pears and McGuinness, Routledge, London, 1961

WWK: Wittgenstein and the Vienna Circle, B. McGuinness ed, Blackwell, Oxford, 1979

\section{Further References}


Black, M. (1964), A Companion to Wittgenstein's 'Tractatus'. New York: Cornell University Press

Conant, J. (2000), 'Elucidation and Nonsense in Frege and Early Wittgenstein' in A. Crary and R. Read (eds.) The New Wittgenstein. London: Routledge.

Diamond, C. (1991), The Realistic Spirit. Cambridge, Massachusetts: MIT Press.

Diamond, C. (2006), 'Peter Winch on the Tractatus and the Unity of Wittgenstein's Philosophy' in A. Pichler and S. Saatela (eds.) Wittgenstein: The Philosopher and his Works. Lancaster: Ontos Verlag.

Frege, G. (1997), The Frege Reader, Beaney (ed.). Oxford: Blackwell.

Frege, G. (1980), The Foundations of Arithmetic, tr. J.L. Austin. Oxford: Blackwell.

Hacker, P.M.S. (1989), Insight and Illusion. Bristol: Thoemmes.

Ishiguro, H. (1969), 'Use and Reference of Names’ in P. Winch (ed.) Studies in the Philosophy of Wittgenstein. London: Routledge.

Malcolm, N. (1986), Nothing is Hidden. Oxford: Blackwell.

Pears, D. (1987), The False Prison volume 1. Oxford: OUP.

Proops, I. (2004), ‘Wittgenstein’s Logical Atomism’ in E.N. Zalta (ed.) The Stanford Encyclopedia of Philosophy (Winter 2004 Edition) URL =

$<$ http://plato.stanford.edu/archives/win2004/entries/wittgenstein-atomism/>.

Russell, B. (1984), Theory of Knowledge, The Collected Papers of Bertrand Russell vol. 7, ed. E.R. Eames. London: Allen and Unwin.

Summerfield, D.M. (1996), 'Fitting versus Tracking: Wittgenstein on Representation' in H. Sluga and D. Stern (eds.) The Cambridge Companion to Wittgenstein. Cambridge: CUP.

Winch, P. (1987), Trying to Make Sense. Oxford: Blackwell. 